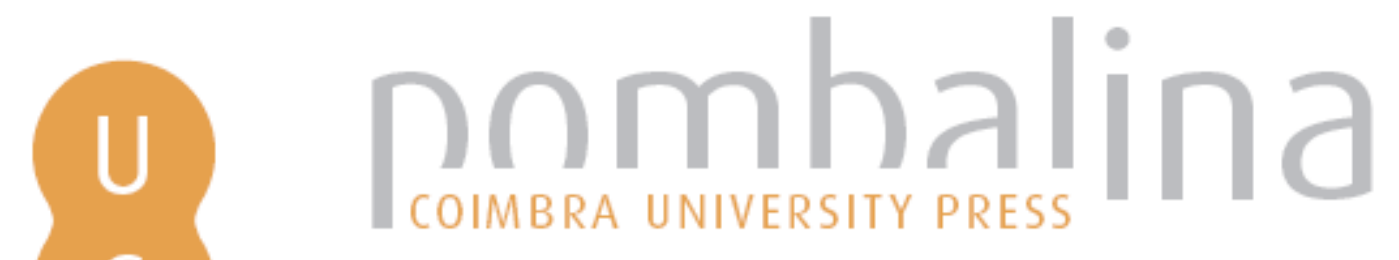

\title{
A matemática e a economia
}

Autor(es): $\quad$ Andrade, João Sousa

Publicado por: Imprensa da Universidade de Coimbra; Gravida

URL

persistente: URI:http://hdl.handle.net/10316.2/32596

DOI: $\quad$ DOI:http://dx.doi.org/10.14195/978-989-26-0485-5_5

Accessed : $\quad$ 26-Apr-2023 11:31:25

A navegação consulta e descarregamento dos títulos inseridos nas Bibliotecas Digitais UC Digitalis, UC Pombalina e UC Impactum, pressupõem a aceitação plena e sem reservas dos Termos e Condições de Uso destas Bibliotecas Digitais, disponíveis em https://digitalis.uc.pt/pt-pt/termos.

Conforme exposto nos referidos Termos e Condições de Uso, o descarregamento de títulos de acesso restrito requer uma licença válida de autorização devendo o utilizador aceder ao(s) documento(s) a partir de um endereço de IP da instituição detentora da supramencionada licença.

Ao utilizador é apenas permitido o descarregamento para uso pessoal, pelo que o emprego do(s) título(s) descarregado(s) para outro fim, designadamente comercial, carece de autorização do respetivo autor ou editor da obra.

Na medida em que todas as obras da UC Digitalis se encontram protegidas pelo Código do Direito de Autor e Direitos Conexos e demais legislação aplicável, toda a cópia, parcial ou total, deste documento, nos casos em que é legalmente admitida, deverá conter ou fazer-se acompanhar por este aviso.

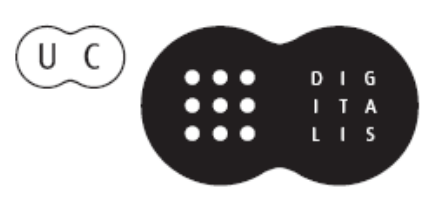


(Página deixada propositadamente em branco) 
MARIA PAULA SERRA DE OLIVEIRA

Coordenadora

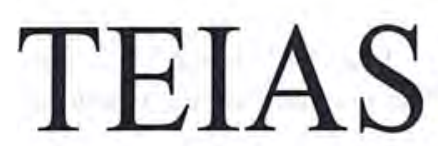

MATEMÁTICAS

Frentes na Ciência e na Sociedade 
(C) Gradiva - Publicações, L. da / Imprensa da Universidade de Coimbra, 2004 Coordenação editorial: Maria Paula Serra de Oliveira

Tradução: Artur Soares Alves

Carlota Isabel Leitão Pires Simões

Francisco José Craveiro de Carvalho

João Filipe Cortez Rodrigues Queiró

José Miguel Dordio Martinho de Almeida Urbano

Lia Sandra dos Santos

Mário da Silva Rosa

Paulo Eduardo Aragão Aleixo Neves de Oliveira

Revisão do texto: Isabel Pedrome

Capa: António Barros [Imprensa da Universidade. Coimbra], com imagem de

E. M. de Melo e Castro, "Fract 010 explod MC", Dezembro de 2003

[Fractal original gerado no Fractint com tratamento no Photoshop 7.0]

Infografia: Estúdios Estímulus [design]

Paginação: António Resende e Victor Hugo Fernandes

Impressão e acabamento: G.C. - Gráfica de Coimbra, L. da

Reservados os direitos para Portugal por:

Gradiva - Publicações, L. ${ }^{\text {da }}$ e Imprensa da Universidade de Coimbra

Gradiva - Publicações, L. ${ }^{d a}$

Rua Almeida e Sousa, 21, r/c, esq. • 1399-041 Lisboa

Telefs. $213974067 / 8 \cdot 213971357 \cdot 213953470$

Fax $213953471 \cdot$ Email: gradiva@ip.pt

URL: http://www.gradiva.pt

Imprensa da Universidade de Coimbra

Rua Antero de Quental, 195 • 3000-033 Coimbra

Telefs. 351239853110

Fax 3512398531 19 e-mail: fjrpress@ci.uc.pt

URL: http://www.imp.uc.pt

ISBN: 972-662-970-5

1." edição: Maio de 2004

Depósito legal n. ${ }^{\circ} 210431 / 04$

OBRA PUBLICADA COM O PATROCÍNIO DE:

CENTRO DE MATEMÁTICA DA UNIVERSIDADE DE COIMBRA DEPARTAMENTO DE MATEMÁTICA DA UNIVERSIDADE DE COIMBRA

FCT Fundação para a Ciência e a Tecnologia

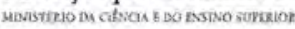


João Sousa Andrade

Faculdade de Economia

da Universidade de Coimbra

\section{A matemática e a economia}

Como digo, nas primeiras aulas, aos estudantes de Introdução à Economia, na Faculdade de Economia, a análise económica, nas suas relações de interdisciplinaridade, apresenta relações privilegiadas com a matemática. Estas relações levam a que os economistas tenham de conhecer e aplicar conhecimentos matemáticos, que, devido ao seu grau de complexidade, têm dificuldade em dominar. Ao longo dos anos, eu e alguns colegas, com esforço e nem sempre com sucesso, procurámos levar essa ideia para a Faculdade de Economia. E hoje, com orgulho, podemos dizer que neste aspecto o futuro está garantido.

Procurarei focar de forma breve os aspectos onde a economia encontrou a matemática e dela necessita. A perspectiva, obviamente pessoal, procura ter em conta o progresso em economia e o apoio que lhe deu a matemática.

Tal como para as restantes ciências sociais, o sucesso da física mecânica no século XIX, teve implicações sobre o que poderia vir a ser uma física social. A procura de uma beleza formal num mundo marcado pela ausência de incerteza vai ser importante no desenvolvimento da economia. A influência da física na forma de pensar dos economistas levou-os a identificar o tempo com o espaço, onde as forças em presença conduziriam aos desejados equilíbrios. O conceito de força acabará por valorizar a análise estática e a estática comparada ${ }^{1}$. Ao mesmo tempo, através da ideia

1 Veja-se sobre o conceito de tempo e a sua utilização em economia Barre (1950), Robinson (1980), Gram (1989) e ainda Burstein (1991). 
de lei tendencial - que o conceito de forças e a sua acção justificavam -, imuniza-se a análise à possível refutação.

A revolução marginalista, iniciada nos anos 70 do século XIX, foi fundamental para a utilização da matemática na economia, sobretudo através das correntes do equilíbrio parcial e do equilíbrio geral. Se hoje o maior desenvolvimento de uma economia matematizada vem dos Estados Unidos, não devemos esquecer que os primeiros economistas matemáticos foram franceses: Cournot $(1838)^{2}$ e Dupuit $(1844)^{3}$, mesmo antes de Léon Walras (1952). O isolamento do Ocidente foi responsável pelo desconhecimento dos trabalhos do russo Dimitriev (passagem do século XIX para o XX) e do japonês Keyshibata (início do século XX).

$\mathrm{O}$ primado do individualismo metodológico, tomado como uma atomic proposition (Whitehead e Russell, 1962) e imposto pela análise dominante, acabará por ter consequências ao nível do papel da matemática na economia. Graças ao individualismo metodológico, a representação do sujeito da economia, do homem da economia, pôde ser feita com base em princípios mínimos (Machlup, 1978), o que torna esta última mais abstracta e propícia à utilização do método hipotético-dedutivo (Andrade, 2000). Assim, o discurso da economia vai-se distinguir do discurso das outras ciências sociais, a ponto de se afirmar que, se o discurso económico se não funda numa representação matemática, pressupõe essa mesma representação (Kolm, 1986). A formalização avançou para formas bastante complexas, embora numa primeira fase limitada a relações determinísticas (Allen, 1963) ${ }^{4}$.

Não bastasse o individualismo metodológico ser aceite, em geral, pelos economistas, Popper (1985) ainda fortaleceu esse postulado ao apresentá-lo como um princípio mínimo de análise, que assim estaria isento da aplicação do seu critério de demarcação científica baseado no falsificacionismo (Nunes, 1996).

A Segunda Guerra Mundial veio determinar a necessidade do planeamento da economia nacional, da produção ao consumo, e os acontecimentos subsequentes, a necessidade de previsão para actuação dos governos dos países capitalistas. O planeamento da produção acabará por levar ao desenvolvimento das técnicas de input-output. O nome do economista de origem russa Leontief, Prémio Nobel em 1973, que apresentou e desenvolveu este tipo de análise, ficará para sempre ligado

2 Veja-se Shubik (1987).

${ }^{3}$ Veja-se Ekelund (1987).

${ }^{4} \mathrm{O}$ livro de Allen, tão marcante, é disso um exemplo. 
aos grandes avanços da economia (Leontief, 1941). Os modelos de input-output conduzem ao desenvolvimento das aplicações de álgebra linear na economia, assim como ao desenvolvimento da programação linear.

Apesar de os economistas também serem escravos da moda, as aplicações do que também ficou conhecido por modelo de Leontief continuam a fazer-se, por exemplo na análise de recursos escassos não renováveis, onde caem certas formas de energia, e no da sua utilização para ter em conta a dinâmica de interdependência de custos e preços entre os ramos da economia.

A necessidade de previsão está hoje tão arreigada nos nossos comportamentos que envolvem decisões correntes ou futuras, que imaginamos que tenha sido sempre assim. Mais, a ausência de previsão passou mesmo a ser considerada sinónimo de incerteza. A incerteza, inerente à tomada de decisões económicas, passou a ser bastante minimizada graças à elaboração de previsões.

Os modelos econométricos ${ }^{5}$ desenvolveram-se primeiro para apoiar decisões dos governos e depois como uma importante actividade privada altamente lucrativa ${ }^{6}$. Não deixa de ser irónico que tenha sido a Cowles Commission (for Research in Economics) (CFRE, 2000b), fundada em 1932, a ser responsável pelo desenvolvimento dos métodos quantitativos na economia, procurando tornar a ciência económica uma ciência mais rigorosa. O interesse central do criador da fundação residia no conhecimento mais preciso do comportamento do mercado financeiro (CFRE, 2000a) ${ }^{7}$. Newton já havia desejado e ensaiado o mesmo.

A previsão criou o seu próprio vício, ou seja, a dependência de modelos econométricos. Por esta razão, assistimos ao desenvolvimento da análise estatística e econométrica, ao aparecimento da necessidade de encontrar aplicações informáticas que auxiliassem o economista.

A moda dos grandes modelos, pesados, de inspiração sobretudo keynesiana, foi abalada com a crise do início dos anos 70. Tratou-se de um fenómeno temporário, ou não fosse a imunização a primeira atitude dos investigadores. Adaptaram-se os modelos tendo em conta um maior peso das decisões de oferta e novas metodologias econométricas, que se desenvolveram. A maior crítica partira de Lucas: os parâmetros dos

5 Para uma história da econometria na análise económica, Hendry e Morgan (1995).

${ }^{6}$ Para uma indicação elucidativa, mas já desactualizada, veja-se Whitley (1994).

${ }^{7}$ Cowles perseguiu esse objectivo mesmo antes da criação da fundação. 
modelos não poderiam ser independentes das alterações de política económica (Lucas, 1972). O progresso em econometria não se fez esperar. Mas, como o provou Sargent, com a hipótese de observationally equivalent (Sargent, 1976), os modelos para serem eficazes necessitam do conhecimento da teoria económica (Walsh, 1998) ${ }^{8}$.

A segunda revolução do individualismo metodológico correspondeu à mera consideração de que o indivíduo racional não devia basear as suas decisões em expectativas sistematicamente enviesadas. Os indivíduos devem agir de forma racional, usando a informação de que dispõem quando tomam as suas decisões. A revolução das expectativas racionais levou a que até para o indivíduo tenhamos de formalizar o comportamento da economia, para que este possa ter em conta as acções de todos os outros. O conhecimento e o desenvolvimento do cálculo recursivo tornou-se uma necessidade ${ }^{9}$. A macroeconomia dinâmica é assim herdeira de Wald, Bellman, e também de Kalman ${ }^{10}$. Convenhamos que para este desenvolvimento muito contribuiu a evolução dos meios de cálculo à disposição dos economistas. Para além dos modelos e das suas soluções, tornou-se igualmente importante a realização de simulações e a análise de sensibilidade das soluções a alterações nos parâmetros. Tratando-se de modelos não-lineares, não é difícil perceber as dificuldades matemáticas e estatísticas que o economista passou a enfrentar ${ }^{11}$.

$\mathrm{O}$ ramo gémeo da economia, o finance, veio a ter uma importância visível nos anos 80 e 90 . Os pais e impulsionadores da nova disciplina serão homens vindos da física. O progresso em finance só foi possível graças à competência desses investigadores. A atribuição em 1990 do Prémio Nobel a Markowitz, Miller e Sharpe foi o primeiro reconhecimento académico do novo ramo. Em 1997, Merton e Scholes, sucedem àqueles economistas.

A complexidade da análise pode facilmente ser apercebida se dissermos que o modelo primeiro da análise financeira consiste num problema de programação quadrática. A análise do valor de mercado dos activos financeiros, e assim do risco, gerou a necessidade de um apoio

${ }^{8}$ Pp. $20-2$.

${ }^{9}$ São disso exemplo Lucas e Stockey (1989) e Ljungqvist e Sargent (2000).

${ }^{10} \mathrm{Na}$ clara formulação de Shubik, "The search for an explicit economic dynamics is a search for the Philosopher's stone», Shubik (2000), p. 2. De referir também Turnovsky (1995).

11 Vejam-se Sargent (1987) e Azariadis (1998). 
estatístico e matemático enorme. Não é pois de estranhar que nos últimos anos os intermediários financeiros tenham sido os principais compradores dos grandes computadores, a par dos sistemas de defesa, nas principais economias.

$\mathrm{O}$ papel que as aplicações informáticas poderiam ter na desestabilização do mercado financeiro levou, no final dos anos 80 , a que se sugerisse a possibilidade de proibição do seu uso. A imaginação e a competência dos que elaboraram e actualizaram esses programas foram suficientes para não gerar opiniões unânimes sobre a situação do mercado financeiro. Esses programas de negócio tornaram-se assim um elemento importante da actividade financeira.

Mas integrar o risco não é o mesmo que integrar a incerteza (Knight, 1921). Esta última, não sendo probabilizável, não poderá integrar aqueles modelos (Nunes, 1998) ${ }^{12}$. E, bem perto dos nossos dias, assistimos a verdadeiros colapsos financeiros no Japão e nos Estados Unidos, tendo estado envolvidos nesses acontecimentos Nobeis da economia, como conselheiros ou mesmo como fundadores e executivos desses intermediários financeiros. O mais recente foi o caso do LTCM (Long Term Capital Management) (Dunbar, 2000). Este fundo entrou em colapso definitivo em Setembro de 1998. Para evitar a sua falência, que seria desastrosa para os Estados Unidos e para a economia mundial, recebeu uma ajuda de 834 milhões de contos (escudos actuais) em 28 de Setembro. Para reanimar o mercado afectado pela impressionante desvalorização do capital da LTCM, a taxa de juro da autoridade monetária norte-americana, do $\mathrm{Fed}^{13}$, será ainda diminuída em $0,25 \%$ em 29 de Setembro, 14 de Outubro e 17 de Novembro. As crises financeiras são de tal forma perigosas, e temidas pelos governos, que estes se dispõem a gastar fortunas para as evitar: a crise dos anos 80 das «Saving and Loan Associations» custou ao governo norte-americano mais do que a Guerra do Vietname.

Apesar das «certezas» e das avaliações dos «riscos» dos economistas, a incerteza continua presente e, de vez em quando, teima em pregar partidas, uma forma de nos lembrar que o mundo não se reduz à representação que dele podemos fazer, por mais formal e bonita que ela seja. Mas os mercados financeiros não seriam o que são hoje sem a formalização matemática dos economistas.

12 Sobretudo cap. IV, pp. 141-179, e anexo 3, pp. 201-214.

${ }^{13}$ Federal Reserve Board. Instituição equivalente ao Banco Central Europeu. 
Se a matemática tivesse a magia de resolver todos os nossos problemas, de formalizar, compreender e predizer, num mundo incerto, o Dr. Dulcamara daria explicações de matemática, Nemorino perderia Adina e Fausto teria tido Mefistófeles a ensinar-lhe matemática esquecendo, entretanto, Margarida.

Se até aqui apenas me referi ao que se passa com o que podemos chamar ramo ortodoxo da análise económica, tem também interesse ver o que se passou com um ramo heterodoxo: o da economia marxista. Não a economia marxista ensinada nos países ex-socialistas, mas a que se estudava fora deles, embora a corrente ortodoxa marxista continuasse agarrada ao materialismo histórico e dialéctico, que posteriormente também degenera em «teoria da regulação», encontrando assim o (falso) apoio positivo de que necessitava. Falso, porque não passava de story telling. Uma outra corrente de economia marxista, positiva, vai desenvolver-se no seguimento da obra de Sraffa (1960). Esta corrente irá basear-se no uso de modelos lineares de produção (Duarte, 1994). A álgebra linear foi usada até aos seus limites. Estes economistas levantarão o problema da medida do capital e aproximam-se dos economistas keynesianos. A teoria do capital interessou os grandes economistas matemáticos até meados dos anos $80^{14}$. Nas faculdades de Economia que optaram por ensinar este ramo de economia marxista, o estudante entrava nas aulas à espera da revolução e encontrava uma matemática complicada para ele e mesmo complexa para a maioria dos economistas.

$\mathrm{O}$ que se passou com a economia marxista é ilustrativo do uso da liberdade de escolha com que nos defrontamos em economia. O economista com conhecimentos de matemática poderia escolher a escola que entendesse mais correcta e prometedora. $\mathrm{O}$ economista sem conhecimentos de matemática não tinha liberdade de escolha...

Falei atrás da segunda revolução do individualismo metodológico e das suas consequências ao nível da formalização. A utilização do conceito de bounded rationality (Simon, 1976 e 1978) não terá destronado aquele outro conceito? Em primeiro lugar devemos insistir no facto de este último conceito ser definido em relação ao primeiro. Também o conceito de racionalidade individual pode ser tomado de forma que o meio em que ela é exercida aja sobre ela. Neste caso, perdemos o mais geral, o aspecto optimizante do comportamento, mas não o seu aspecto maximizante (Sen, 1996).

${ }^{14}$ Kurz (1987) e Pasinetti e Scazzieri (1987). 
A simplicidade de representação do indivíduo é agora substituída pela complexidade. As interacções sucedem-se. A inteligência artificial, em geral, e as redes neuronais, em particular, têm aqui a sua porta grande de entrada na economia. Em aspectos particulares já haviam entrado. Como disse Sargent (1993), o economista das expectativas racionais era um super Deus; criava indivíduos que conheciam melhor do que ele (economista) o funcionamento da economia, e afinal deve criar indivíduos mais à sua semelhança, que erram e aprendem, que voltam a errar e a aprender ...

Em suma, um comportamento menos simples do homem da economia acarreta uma maior complexidade da análise económica, e por essa via a complexidade dos meios de análise matemática. No mesmo sentido, acaba por apontar a introdução das emoções nas escolhas racionais dos indivíduos (Damásio, 1994).

Há muito que os economistas abandonaram a escravatura do realismo das hipóteses (Friedman, 1953) como base de partida para a investigação. Por isso, a introdução de formas não ilimitadas de racionalidade deixa o economista num dilema. A introdução de um realismo no comportamento do homem da economia tem de ser avaliada do ponto de vista dos seus resultados. Não adianta bater no nosso homem. Ele não protesta. Como disse Espinosa, o conceito de cão não ladra! Para já, sabemos que os resultados daqueles modelos estão demasiado dependentes de hipóteses ad hoc sobre comportamentos.

Dilema idêntico se coloca ao problema do agente representativo na macroeconomia dinâmica. Ninguém duvida que tomar um agente que representa todos os outros pode ser uma hipótese demasiado irrealista. Mas a contrapartida é a complexidade matemática que resulta de tomarmos agentes heterodoxos. Para além, mais uma vez, de aumentarem as hipóteses ad hoc sobre comportamentos que resultam do acréscimo de parâmetros do modelo.

$\mathrm{O}$ tratamento da informação assimétrica é muito interessante para o economista. No entanto, as exigências de conhecimentos matemáticos são bastante grandes, pelo que não são muitos os economistas com capacidade para formalizar tais comportamentos, que são importantes sobretudo em economia financeira.

Já houve tempos em que os economistas pensaram a economia como a ciência social abrangente das restantes ${ }^{15}$. A questão deixou de fazer sentido. O que hoje temos é um método usado em economia que, em

15 Osório (1996) tinha essa posição. Sobre este autor veja-se nesta obra o prefácio do professor Jacinto Nunes. 
algumas situações, se impõe nas outras ciências sociais. $\mathrm{O}$ método de investigação começou a ser conhecido por outras disciplinas através de um sociólogo e de um economista. O rigor de análise e a elegância de apresentação têm com certeza a sua importância neste reconhecimento (Coleman, 1990 e Becker, 1981).

Uma corrente da economia, designada por «economia dos ciclos reais», introduziu uma nova metodologia de investigação, de que os chamados modelos de equilíbrio geral também fazem uso. A formalização bastante avançada e, em geral, a utilização de programação dinâmica, permite a representação da economia baseada em comportamentos definidos $a$ priori. A sua construção depende da opinião do investigador sobre o que deve ou não ser incluído. Se é assim que se investiga em qualquer ciência, aqui o problema é diferente devido ao tipo de não refutação que é usado. Em geral o número de parâmetros é elevado e a escolha dos seus valores feita de forma a que o conjunto das equações do modelo produza soluções próximas dos valores efectivos. Se a reprodução dos valores das variáveis, para as quais o modelo foi construído, for boa, então o modelo é bom. Se a reprodução for má, voltamos à calibragem do modelo, ou seja, à escolha de novos valores para os parâmetros (King, 1995, e King e Rebelo, 2000). Tal como num treino de Fórmula Um. Só que ninguém, até hoje, atribuiu o título de cientista a Schumacher.

Esta metodologia é um retrocesso ao verificacionismo do início do século XX (Nunes, 1996, e Jacob, 1980). Podemos classificar esta prática como jogos de economia que apenas os que possuem elevados conhecimentos de matemática podem jogar, mas não como construção científica.

Em suma, a matemática surge-nos como um instrumento de análise do qual é impossível prescindir e sem o qual o progresso não será possível. Mas o seu uso de forma abusiva pode afastar a análise do seu objecto de estudo e não respeitar condições metodológicas de investigação ${ }^{16}$. Afinal, a economia pode ser tomada como aquilo que os economistas fazem, e nisso, estes, fazem um uso crescente da matemática.

Feynman (1989) disse que lamentava quem não tinha conhecimentos de matemática porque não podia apreciar a natureza. Por sua vez, Kolm $(1986)^{17}$ disse que o mundo, hoje, seria bem diferente se Marx, em vez de na sua juventude ter estudado filosofia, tivesse estudado matemática.

${ }^{16}$ Ainda que se aceite a posição de Hanson (1961).

17 P. 106. 


\section{Referências}

Allen, R. G. D. (1963) - Mathematical Economics. Londres: Macmillan.

Andrade, J. S. (2000) - Algumas Observações sobre a Metodologia da Economia. Episteme, 5-6, pp. 39-76.

Azariadis, C. (1998) - Intertemporal Macroeconomics. Oxford: Blackwell Publishers.

Barre, R. (1950) - La Période dans l'Analyse Économique, une approche à l'étude du temps. Paris: Société d'Édition d'Enseignement Superieur.

Becker, G. (1981) - A Treatise on the Family. Cambridge, Ma.; Harvard University Press.

Burstein, M. (1991) - History versus Equilibrium, Joan Robinson and Time in Economics, in The Joan Robinson Legacy. I. Rima ed. Armonk: M. E. Sharpe, pp. 49-61.

CFRE (2000a) - Alfred Cowles, 3. ${ }^{a}$ ed., Founder and President, Setembro 1932 Setembro 1934. http://cowles.econ.yale.edu, Yale University.

CFRE (2000b) - A Short History. http://cowles.econ.yale.edu, Yale University. Coleman, J. (1990) - Foundations of Social Theory. Cambridge, Ma.: Harvard University Press.

Cournot, A. A. (1838) - Recherches sur les Principes Mathématiques de la Théorie des Richesses. Paris: Livraria Hachette.

Damásio, A. (1994) - O Erro de Decartes, Emoção, Razão e Cérebro Humano. Lisboa: Publicações Europa-América.

Duarte, A. D. (1994) - Valeur, Prix, Dynamique non-Proportionelle. Une mise en perspective des apports critiques et constructifs du courant neocambridgien, 550 pp.; Coimbra: Universidade de Coimbra.

Dunbar, N. (2000) - Inventing Money, the Story of Long-Term Capital Management and the Legends Behind It. Chichester: John Wiley \& Sons.

Dupuit, A. J. E. J. (1844) - De la Mésure de l'Utilité des Travaux Publics. Annales des Ponts et Chaussées, 13.

Ekelund, R. (1987) - Dupuit, Arsène-Jules-Emile Juvenal, in The new Palgrave: A dictionary of economics. J. Eatwell, M. Milgate and P. Newman eds. Londres: Macmillan Press, pp. 943-4.

Feynman, R. (1989) - O que é uma Lei Física. Lisboa: Gradiva.

Friedman, M. (1953) - The Methodology of Positive Economics, in Essays in Positive Economics. M. Friedman ed., Chicago: The University of Chicago Press, pp. 3-43.

Gram, H. (1989) - Ideology and Time: criticisms of General Equilibrium, in Joan Robinson and Modern Economic Theory. G. Feiwel ed., Londres: Macmillan Press, pp. 285-302. 
Hanson, N. (1961) - Is There a Logic of Discovery?, in Current Issues in the Philosophy of Science. H. Feigl and G. Maxwell, eds., Nova Iorque: Reinehart and Winston, pp. 20-35.

Hendry, D., M. Morgan eds. (1995) - The Foundations of Econometric Analysis. Cambridge: Cambridge University Press.

Jacob, P. (1980) - Comment peut-on ne pas être Empiriste?, in De Vienne à Cambridge. L'héritage du Positivisme Logique. P. Jacob, ed., Paris: Gallimard, pp. 7-52.

King, R. (1995) - Quantitative Theory and Econometrics. Federal Reserve Bank of Richmond Economie Review, 81, pp. 53-105.

King, R., S. Rebelo (2000) - Resusciting Real Business Cycles. Rochester Center for Economic Research, Working Paper No. 467.

Knight, F. (1921) - Risk, Uncertainty and Profit. Chicago: University of Chicago Press.

Kolm, S. C. (1986) - Philosophie de l'Économie. Paris: Seuil.

Kurz, H. (1987) - Capital Theory: Debates, in The New Palgrave: A Dictionary of Economics. J. Eatwell, M. Milgate and P. Newman, eds., Londres: Macmillan Press, pp. 357-62.

Leontief, W. (1941) - The Structure of the American Economy, 1919-1929. Cambridge, Ma.: Harvard University Press.

Ljungqvist, L., T. Sargent (2000) - Recursive Macroeconomic Theory. Cambridge, Ma.: The MIT Press.

Lucas, R. (1972) - Expectations and the Neutrality of Money. Journal of Economic Theory, 63, pp. 103-124.

Lucas, R., N. Stockey (1989) - Recursive Methods in Economic Dynamics. Cambridge, Ma.: Harvard University Press.

Machlup, F. (1978) - Methodology of Economics and Other Social Sciences. Nova Iorque: Academic Press.

Nunes, J. (1996) - Introdução à Epistemologia e Metodologia Económicas - O Pós-Positivismo. Coimbra: Boletim de Ciências Económicas.

Nunes, J. (1998) - O Pensamento de Keynes. Lisboa: Imprensa Nacional - Casa da Moeda.

Osório, A. H. (1996) - A Matemática na Economia Pura: a Troca. Lisboa: Banco de Portugal.

Pasinetti, L., R. Scazzieri (1987) - Capital Theory: Paradoxes, in The New Palgrave: A Dictionary of Economics. J. Eatwell, M. Milgate e P. Newman, eds., Londres: Macmillan Press, pp. 363-68.

Popper, K. (1985) - The Rationality Principle, in Popper Selections. D. Miller, ed., Nova Iorque: Princeton University Press, pp. 357-365.

Robinson, J. (1980) - Time in Economic Theory, in Further Contributions to Modern Economics. J. Robinson, ed., Oxford: Basil Blackwell, pp. 86-95. 
Sargent, T. (1976) - The Observational Equivalence of Natural and Unnatural Rate Theories of Macroeconomics. Journal of Political Economy, 84:3, pp. 631-640.

Sargent, T. (1987) - Dynamic Macroeconomic Theory. Cambridge, Ma.: Harvard University Press.

Sargent, T. (1993) - Bounded Rationality in Macroeconomics. Oxford: Clarendom Press.

Sen, A. (1996) - Maximization and the Act of Choice. Temi di Discussione, Banca de Italia, 270, Maio.

Shubik, M. (1987) - Cournot, Antoine Augustin, in The New Palgrave: A Dictionary of Economics. J. Eatwell, M. Milgate e P. Newman, eds., Londres: Macmillan Press, pp. 708-712.

Shubik, M. (2000) - The Theory of Money. Cowles Foundation Discussion Papers, 1253.

Simon, H. A. (1976) - From Substantive to Procedural Rationality, in Method and Appraisal in Economics. S. Latsis, ed., Cambridge: Cambridge University Press, pp. 129-148.

Simon, H. A. (1978) - Rationality as Process and as Product of Thought. American Economic Review, 68:2, pp. 1-16.

Sraffa, P. (1960) - Production of Commodities by Means of Commodities. Cambridge: Cambridge University Press.

Turnovsky, S. (1995) - Methods of Macroeconomic Dynamics. Cambridge, Ma.: The MIT Press.

Walras, L. (1952) - Élements d'Économie Politique Pure, ou théorie de la richesse sociale. Paris: Librairie Générale de Droit et de Jurisprudence (1874).

Walsh, C. (1998) - Monetary Theory and Policy. Cambridge, Ma.: MIT Press.

Whitehead, A., B. Russell (1962) - Principia Mathematica, 1927, Paper Edition to $* 56$. Cambridge: Cambridge University Press.

Whitley, J. (1994) - A Course in Macroeconomic Modelling and Forecasting. Londres: Harvester Wheatsheaf. 


\section{$\begin{array}{llllll}\text { C I E } & \mathbf{N} & \mathbf{C} & \mathbf{A}\end{array}$}

mitiram realizar com sucesso tarefas tão distintas como a programação de um voo a Marte, a previsão de resultados eleitorais, a explicação do funcionamento de alguns mecanismos do sistema nervoso, ou a abordagem critica de obras de arte e de textos literários. Da ciência à sociedade, dos grandes avanços técnicos à solidez de uma argumentação lógica, a Matemática constrói teias de uma imensa flexibilidade resultante do carácter universal da sua linguagem.

Neste livro, personalidades de diferentes universos dão o seu testemunho sobre a forma como usam as teias matemáticas para tecer a sua própria visão do mundo.

Maria Paula Serra de Oliveira é professora de Matemática na Faculdade de Ciências e Tecnologia da Universidade de Coimbra. 